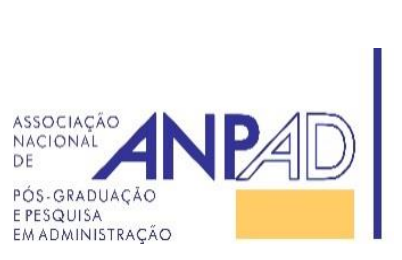
Available online at http://www.anpad.org.br/bar
BAR, Rio de Janeiro, v. 15, n. 1, art. 4, e170061, 2018

\title{
Cultural Meanings and Consumers' Discourses about Their Brand Abandonment
}




\begin{abstract}
Although we know a lot about how brand meanings are created and perpetuated in relation to and through cultural discourses, remarkably little work has been done in the marketing field to develop a better comprehension as to how brand meanings are enacted through distancing behaviors, such as brand abandonment. In the marketing literature, abandonment has usually been associated with relationship crises, most commonly as the result of consumer dissatisfaction. This study investigates consumers who abandoned previously consumed brands in two distinct product categories, soft drinks and automobiles. Through investigation of two emblematic brands - CocaCola and Fiat - the analysis illustrates cultural discourses that consumers use to give meanings and socially negotiate their brand abandonment. Considering the repertoire of meanings attached to both the brands and consumers' commitment to their distancing behavior, the analysis presents three types of brand abandonment: (a) contingent, (b) balanced and (c) aversive. This paper also presents brand abandonment as an enabler of social distinctions, highlighting two discrete discourses promulgated and perpetuated by consumers: (a) Life evolution, and (b) Rationality, self-control and sovereignty.
\end{abstract}

Key words: brand; consumption abandonment; Coca-Cola; Fiat; consumer culture theory. 


\section{Introduction}

Brands and branding have become a central topic in marketing literature and managerial activities (Allen, Fournier, \& Miller, 2008; Schroeder, 2015). From a cultural perspective, brands are cultural resources that resonate and co-create the cultural milieu in which they are embedded (Holt, 2006). In this sense, more than just a sign or a name, brands are carriers of meaning and value, reflecting broad societal, cultural, and ideological codes (Schroeder, 2015). For these reasons, academic and market researchers have put a great deal of effort into understanding how brand meanings are created and perpetuated in relation to and through cultural discourses (Allen et al., 2008; Holt, 2005; Thompson, 2004).

Although we know a lot about how meanings are created through interest, consumption and affiliation, remarkably little work has been done in the marketing field to understand cultural meanings spotlighted in consumers' discourses about their brand abandonment. Suarez and Chauvel (2012) define abandonment as the process of giving something up which was previously consumed. As such, brand abandonment refers to the process of reducing or eliminating consumption of previously valued and consumed brands. The present research contributes to expanding our comprehension of brands by addressing two distinct yet closely related questions: (a) Considering the repertoire of meanings attached to brands and consumers' commitment to this distancing behavior, what types of brand abandonment exist? (b) What discourses are enacted by consumers through brand abandonment? The research uses a qualitative methodology to collect and analyze data obtained from in-depth interviews with fourteen Brazilian consumers who gave up or more precisely abandoned two different iconic brands: Coca-Cola (Holt, 2005) and Fiat (Suarez \& Belk, 2017).

Previous studies of consumption abandonment addressed the phenomenon as an unwanted consequence of failure or conflict situations providing the impetus for consumers to give up certain suppliers (Jiang, Zhan, \& Rucker, 2014; Prentice, 2014). In understanding abandonment as resulting from dysfunctional relationships, the existing literature presents a theoretical gap, failing to broadly understand how cultural meanings contribute to brand abandonment. As our study suggests, this cultural perspective complements extant studies, evidencing abandonment that occurs even when consumers are satisfied. The study analysis presented herein illustrates cultural discourses used by consumers to give meanings and socially negotiate their brand abandonment. Thus, brand abandonment is framed as an enabler of social distinctions and narratives, highlighting two discrete discourses promulgated and perpetuated by consumers: (a) Life evolution, and (b) Rationality, self-control and sovereignty.

The research also responds to recent calls for greater understanding of the processes of brand depreciation and consumers' loss of interest (Parmentier \& Fischer, 2015). Unlike previous studies that investigated meanings created by antibrand activists (Giesler, 2012; Izberk-Bilgin, 2012), this research investigates distancing and symbolic departures created by regular consumers in their more routine movement away from their previously preferred brands.

The analysis presents three types of brand abandonment: (a) contingent, (b) balanced, and (c) aversive, evidencing multiple possibilities for distancing behaviors. Although aversive abandonment promulgated by activists or dissatisfied customers are more vocal and visible, it is fundamental for academics and brand managers to understand the entire spectrum of distancing dynamics.

The components of this paper are as follows: first, the literature review presents and frames our understanding of the discourse and abandonment concepts including a presentation of existing theoretical gaps. After presenting the methods used in the study, the analysis articulates the types of brand abandonment and interprets two different cultural discourses underlying brand abandonment. Finally, there is a discussion of the research implications and directions for future research. 


\section{Delineating Abandonment}

Loss of customers has always haunted companies. In marketing literature, this topic has been treated from a variety of perspectives and terminologies: termination of the association, withdrawal, disengagement, discontinuation, uncoupling and break-ups (Dwyer, Schurr, \& Oh, 1987); churn (Lemmens \& Croux, 2006); switching behavior (Jiang et al., 2014); exit (Hulbert, Pitt, \& Ewing, 2003); customer defection (Prentice, 2014); skip (Anderson \& Jaggia, 2012); disadoption (Fournier, Alvarez, \& Avery, 2012; Lehmann \& Parker, 2012); and abandonment (Hogg, Banister, \& Stephenson, 2009; Suarez, 2014; Suarez \& Chauvel, 2012).

In most studies, abandonment is not in itself the object under investigation, but a consequence or by-product of the range of processes examined, such as satisfaction, loyalty, switching behavior, etc. Recently, Lehmann and Parker (2012) called for a more systematic attention to disadoption in an effort to integrate perspectives into a unified theory. They define disadoption as "the process of cessation or substantial reduction in the use of a previously valued behavior or possession" (Lehmann \& Parker, 2012 , p. 313). The authors stress the specificity of this phenomenon differentiating it from choice and adoption behaviors, since it is not a binary choice (yes or no), but a process that can be gradual or partial and filled with uncertainties. Disadoption might include comings and goings and is seen as quite different from consumption decisions. In every case, however, disadoption is always supported by prior experiences as consumers know what they are disadopting.

Suarez and Chauvel (2012) present a broader concept, defining abandonment as the process of giving up something previously consumed. While the term disadoption suggests a decision that was made by the consumer, abandonment also includes non-reflective dynamics; e.g. abandoning without effectively making the decision, and other non-choice situations, such as when the product is no longer within the consumer's means. The present paper uses the term abandonment for the sake of consistency and to denote the focus on cultural rather than cognitive aspects related to this process. Category abandonment is different from brand abandonment. In the first case, consumers are not interested in the consumption anymore. This is the case when someone quits smoking or sells a car, without buying a new one to substitute for the previous one. The present research advances abandonment discussion, addressing consumers who continue to buy the category, but decide on a different brand, thus distancing from a previously preferred product.

Hogg, Banister and Stephenson (2009) depict differences and articulation of avoidance, aversion and abandonment. While aversion is more affective, involving dislikes, disgusts and revulsion, avoidance refers to the act of staying away from something. Abandonment is usually related to avoidance, but not always to aversion, since consumers may abandon neutral or even beloved products/brands.

Discussing brand avoidance is distinguished specifically from abandonment, because you can avoid something you never consumed. Lee, Motion and Conroy (2009) affirm that there are three reasons for consumers to avoid a brand. The first one they called experiential, which is dealing with the conflict between consumers' expected and actually perceived quality, translating those impressions into dissatisfaction with the product. Second is identity avoidance, which is related to the symbolic consumption of brands. As consumers seek a personal and social identification through consumption, brands that don't match the image they are trying to convey are rejected. Finally, there is a moral issue as motivation for rejection. This is the case when consumers avoid a brand based on its values and impact on society.

The process of brand abandonment was peripherally addressed through the lens of brand relationship (Fournier, 1998). Fournier (2014) suggests that brand disadoption can be triggered both by consumers and companies. The author describes possible mismatches between brands and consumers as motivation for break ups. Sometimes, the mismatch preexists the relationship, and in other cases, results from changes in consumers' lives or, in some cases, shifting in brand quality and positioning. Consumers may also disadopt brands when they feel betrayed by a company's inadequate behavior, 
such as ignoring complaints, thus delivering inattentive or rude service. Fournier (2014) reminds us that even if consumers break-up with a brand, the relationship is not completely over, but simply changes its form. Former consumers continue to maintain some form of relationship with the brand, even though it becomes a negative one, characterized by disappointment and rage. When addressing relationship ruptures, Fournier (1998) generally describes dyadic dynamics, occurring between the consumer and a specific brand. However, little is known about socio-cultural discourses enacted through brand abandonment.

Thompson, Rindfleisch and Arsel (2006) suggest that consumers avoid brands when their emotional-branding promises are viewed as inauthentic. With brands that violate their own emotional promises, there is greater susceptibility to doppelgänger brand image, that is, a family of disparaging images, stories, parodies and criticisms that circulate in popular culture, competing with the emotionally resonant meanings suggested by brand management. Parmentier and Fischer (2015) investigated how fans or users themselves foster doppelganger brand images, thus contributing to the process of audience dissipation of serial brands. Muñiz and Schau (2005) investigate abandonment promoted by the producer. The research reveals the complex interplay between consumers, brands and organizations, investigating a community united around a product (Newton), but against the company. The strong storytelling orientation against Apple and the product discontinuation serve as mechanisms of legitimation, delineating the community emancipation from the market and technological ideologies.

Johnson, Matear and Thomson (2011) state that anti-brand retaliatory behaviors are more frequent when the brand is important to consumers' self-concept or self-image. In contrast, anti-brand actions are less likely when relationships are low in self-relevance, but high in trust, commitment, and satisfaction. In such cases, even after relationship dissolution, consumers seem less motivated to complain to third parties, give negative word of mouth comments and perform illegal acts such as theft, threats, and vandalism.

In summary, brand abandonment is usually peripherally addressed in studies centered on satisfaction, brand relationship and brand avoidance. Although addressing the symbolic and emotional facets of distancing behaviors, doppelgänger brand studies portray consumers as intentionally attacking and destabilizing a brand (Muñiz \& Schau, 2005; Parmentier \& Fischer, 2015; Thompson, Rindfleisch, \& Arsel, 2006). Our present study enriches this cultural perspective, demonstrating abandonment meanings created by regular consumers in their almost banal movement to distance from a previously preferred brand.

\section{Discourse as a Collective Phenomenon}

Discourses have different meanings within marketing literature, therefore, the threshold issue of need is clarification of the present research approach and its fundamental premises and scope. An existential-phenomenology discourse refers to consumers' everyday speech and writing acts. Within this perspective, individual discourses offer personal meanings and first-person perspectives and experiences, as gathered from the interviews and conversations. When analyzing discourses, the main focus is on the individual, apprehending consumers authentic report of experiences and of the ways in which they subjectively constitute relations to objects and events in their lives (Moisander, Valtonen, \& Hirsto, 2009).

Postmodernist or poststructuralist perspective, as applied in the present research, understands discourse not as content of a single mind, but rather as a collective pattern of language, resulting from cultural, historical and social conditions (Bristor \& Fischer, 1993; Moisander et al., 2009). This nonsubjective perspective emphasizes discourses intertextual and inter-discursive nature, since every speech practice precedes and exceeds the speaker. Discourses, in this sense, are always social texts, built from pre-existing discourses, genres and registers, molding and giving meanings to particular versions of individuals' experience (Moisander et al., 2009). Finally, discourses are not restricted to ideational 
forms, but are materialized in the institutions and social practices organizing people's lives (Reckwitz, 2002).

Although postmodernity assumes discourses are of a fluid and situated nature, considering that meanings are perpetually changing according to content and contextual configurations, researchers such as Kozinets (2008) advocate for the investigation of discourses nodal points, that can be understood as centers of gravity around which signifiers float. According to the author, consumer narratives are always imbued with ideologies and through investigation of these complexities it is possible to unveil the evaluative and institutionalizing function of ideology. As ideological structures, these nodal points create a strong sense of individual and societal identity, influencing discourses presented in personal communication as well as in mass cultural texts.

Thompson (2004) presents a similar argument when claiming that individuals are never under the domain of a single hegemonic discourse, but more likely permeated by multiple and competing discourses. At the same time, the author maintains the relevance of social institutions such as the family, religion, professional work, and education as discourse producers, constructing and legitimizing social hierarchies and status distinctions, establishing normative identity positions.

Consumer culture researchers have investigated broadly how discourses and ideologies permeate, channel and legitimate consumption (Arnould \& Thompson, 2015). Recent research, for instance, evidences the process through which discursive systems shape technology consumption (Kozinets, 2008); taste (Arsel \& Bean, 2013), identity projects (Arsel \& Thompson, 2011); marketplace legitimation (Humphreys, 2010); resistance to consumption and consumer activism (Giesler, 2012; Izberk-Bilgin, 2012; Varman \& Belk, 2009). Despite this significant body of research, we know little about discourses created and articulated during the brand abandonment process. The present research aims to fill this gap, more fully understanding the meanings, discourses and ideological underpinnings which underlie the spectrum of brand distancing behaviors.

\section{Empirical Context and Research Methodology}

According to Holt (2005), iconic brands represent more than the product or service they provide. They become part of a certain culture and consciousness. An iconic brand carries a story that circulates in culture and that can address cultural tensions of the moment. Aiming to reach a deeper understanding of the brand abandonment process from a cultural perspective, this study analyzed two different global brands quite emblematic in Brazil: Coca-Cola and Fiat.

Coca-Cola is one of the few brands holding the status of a global icon, having been one of the examples depicted by Holt (2005) to delineate cultural branding strategy. Leveraged by a mythic NorthAmerican status, incorporating values such as youth and happiness, Coca-Cola raises both admiration and rejection worldwide. Recent studies, for instance, evidence Coca-Cola tangled in collective rejection and anti-consumption movements motivated by religious (Izberk-Bilgin, 2012) and nationalistic ideologies (Varman \& Belk, 2009). Coca-Cola also suffers for its resonance within the soft drink category, raising critiques for its impact on healthy habits especially among children and adolescents (Massyliouk \& Campos, 2016).

In recent years, news and statements from doctors, nutritionists and other experts present the negative aftereffects of soft drink products, including concerns about the sugar and caffeine content, as well as acidity of various drinks, and resultant impact on dental health and obesity (Hattersley et al., 2009). In several countries, including Brazil, regular consumption of soft drinks has been used as an indicator of unhealthy food patterns (Instituto Brasileiro de Geografia e Estatística [IBGE], 2014). According to a recent survey (Associação Brasileira das Indústrias de Refrigerantes e de Bebidas não Alcoólicas [ABIR], n.d.), consumption of soft drinks in Brazil fell by $21.25 \%$ between 2010 and 2016. In this sense, Coca-Cola presents itself as a brand with both positive and negative meanings, offering 
itself as a symbolic resource that encompasses important contemporary cultural contradictions and symbolisms to be investigated through the everyday movements of brand abandonment.

In the same fashion, as one of the most enduring and important brands in the Brazilian automotive market, the Fiat brand also carries several distinct meanings associated with the category, such as masculinity, independence, achievement and wealth (DaMatta, Vasconcelos, \& Pandolfi, 2010). Automobiles are also at the center of debates about urban mobility, which are now being contested by groups concerned about sustainability (Suarez \& Chauvel, 2012).

Historically, the product's high price has restricted its consumption to the wealthiest and, for this reason, cars are more than transportation, but a statement of economic and social status, distancing the elite from the plebeians, both physically and symbolically (DaMatta et al., 2010). Although the Fiat brand insinuates itself into positive meanings connected to automobiles, it becomes the affordable dream of consumption for the class of emerging Brazilian consumers (Suarez \& Belk, 2017). Between 2005 and 2016, the company has been the market leader, presenting in its portfolio four models within the 10 top-selling cars - all concentrated within the low end of the market. Harboring oppositional meanings, such as differentiation vs. inclusion and achievement vs. affordability, Fiat cultural resonance was perceived during the 2013 Brazilian protests, when a Fiat jingle was appropriated by demonstrators as the anthem for the demonstrations. According to Suarez and Belk (2017), this appropriation resulted from the institutional resonance carried by this brand.

At the period in which the study was conducted, from 2013 to 2016, Fiat and Coca-Cola were the leading brands in sales in Brazil within their respective categories and market segments. We believe that relevancy in the marketplace triggers continuous exposition of these brands through advertisements, point-of-sale displays, and other consumers' acquisition, turning brand abandonment into a vehicle of social significance which is more complex as well as more relevant. For example, consumers who no longer choose to drink Coca-Cola need to explain their preference at parties and celebrations where the drink is being served. As Suarez and Casotti (2015) suggest, brand switching in the purchase of an automobile needs to be intensively negotiated between family members and other consumers who in many cases are still involved with the brand.

The choice of Coca-Cola and Fiat as brands to be investigated took into account not only the relevance in the market, but also the differences they encompassed, since cars and soft-drinks are quite different in their consumption process (Desjeux, Suarez, \& Campos, 2014). While automobiles have long purchase cycles and high financial investment, soft drinks have low out-of-pocket investment and fast consumption cycles, most often related to habit and established flavor preferences. When investigating brand abandonment, these distinct categories thus offer the possibility of understanding on the one hand distances that result following long analytical processes, comparison and weighting of factors (automobile), and, on the other hand, processes involving changes in everyday habits (soft drink).

\section{Data collection and analysis}

We interviewed fourteen ex-consumers - seven informants being previous Fiat brand owners and seven who had abandoned consumption of Coca-Cola. Recruitment used as a primary filter, the identification with the phrase: I was, but today I am no longer a consumer of Fiat / Coca-Cola. Interviewee recruitment was carried out by a specialized professional, aiming at distance from the researchers' own networks in order to achieve more diversity. This strategy gathered informants who varied in terms of family status (single, married, and divorced; with and without children), education (from high school to graduate degrees) and occupation. This served as a tool to capture discourse not as content of specific profiles or groups, but instead as a collective pattern of language, resulting from cultural, historical and social conditions (Bristor \& Fischer, 1993; Moisander et al., 2009). Table 1 summarizes informants profile: 
Table 1

Informants Profile

\begin{tabular}{ccccc}
\hline Pseudonym & Age & Occupation & $\begin{array}{c}\text { Abandoned } \\
\text { Brand }\end{array}$ & Present Brand \\
\hline Talita & 31 & Secretary & $\begin{array}{c}\text { COCA-COLA } \\
\text { ZERO }\end{array}$ & $\begin{array}{c}\text { GUARANÁ } \\
\text { ANTARTICA }\end{array}$ \\
\hline Vanessa & 55 & Teacher & COCA-COLA & GUARANÁ \\
\hline Luana & 31 & Teacher & COCA-COLA & SUCOS \\
\hline Marcelo & 43 & Business owner & COCA-COLA & GUARANÁ (ZERO) \\
\hline Luis & 28 & Operational Supervisor & COCA-COLA & SODA LIMONADA \\
\hline Caetano & 36 & History Teacher & COCA-COLA & PEPSI \\
\hline Caio & 31 & Administrative Assistant & COCA-COLA & GUARANÁ NATURAL \\
\hline Bernardo & 36 & Production manager & Fiat Uno & SANDERO STEPWAY \\
\hline Carla & 44 & Teacher & Fiat PALIO & Hiat Uno \\
\hline Humberto & 45 & Physiotherapist & Fiat Uno & CHEVROLET ASTRA \\
\hline Luciano & 31 & Realtor & Fiat IDEA & VOLKSWAGEN \\
\hline Marcio & 34 & Web Designer & Fiat TIPO & FORD FIESTA \\
\hline Andressa & 43 & Secretary & Fiat PALIO & VOLKSWAGEN FOX \\
\hline Teresa & 30 & Technology analyst & Fiat Uno & PEUGEOT 207 \\
\hline
\end{tabular}

Methodologically, brand abandonment research is challenging. As Wilk (1997) alerts, while consumption is concrete and visible, non-consumption leaves no trace. Thus, abandonment investigation is about an absence, which is impossible to observe, such as for example, contextualized interactions with abandoned brands. For this reason, in the present study, we used in-depth interviews and projective techniques for data collection. We understood each interview as a performance in which people enacted cultural meanings and systems of representation (Fischer, Castilhos, \& Fonseca, 2014; Moisander et al., 2009). More than personal experiences, our interest focused on understanding discursive resources that informants used to legitimize their brand abandonment.

The interviews began with grand-tour questions (McCracken, 1988), about the participants' background, personal interests, life style and then switched to an exploration of their brand relationship accounts. The use of projective techniques was inspired by the classical study about consumers who do not buy instant coffee, despite positive taste test results (Rook, 2006). According to this author, projective techniques provide not only triangulation around a central topic but serves to break the monotony of interviews. We also followed Moisander, Valtonen and Hirsto (2009) in our use of projective techniques aimed at promoting cultural talk. Thus, in this sense, our approach does not aim to investigate individual unconscious content, but rather to analyze the cultural discourse established from the projective stimuli. We initially asked informants to describe three different consumers: (a) a typical consumer who loves the brand; (b) a consumer who, like themselves, abandoned the brand; and finally (c) a consumer who never experienced the brand. A second projective exercise asked informants to describe the brand as if describing a person.

All interviews were recorded and transcribed, accounting for more than 234 pages of interview transcripts. The shortest interview lasted 40 minutes and the longest around one hour and a half. Analysis aimed at understanding consumers' interviews as products of discursive practice. In the first stage, 
summaries were developed through careful reading of each interview and highlighting feelings, stories and arguments within the discourses. After an iterative, part-to-whole process of hermeneutic analysis (Thompson, 1997), compiling a holistic understanding of each informant, interviews were codified (Belk, Fischer, \& Kozinets, 2012), generating 64 different codes. Finally, interviews were compared, looking for similarities and differences to refine the concepts that will be presented in the next section.

\section{Results}

\section{A typology of brand abandonment}

Brand abandonment refers to the process of reducing or eliminating the consumption of certain brands which were previously valued. As this definition suggests, manifestations of brand abandonment vary. A comprehensive definition of abandonment includes and may be blended with underlying behavior such as switching brands or category abandonment. This broader definition allows understanding abandonment as a multifaceted process in consumers' lives rather than as a definite, discrete event. While some informants showed little commitment to brand abandonment, others demonstrate a more resolute abandonment.

In the first case, although they reduced or gave up their consumption, the consumers still consider resumption of consumption at some future time. In the second case, rather than reestablishing consumption, some informants declare a resolute determination to stay away from a previously preferred brand. Thus, we suggest a typology of brand abandonment differentiating two different dimensions: the repertoire of meanings attached to the brands and the level of commitment to the abandonment, i.e., the extent to which brand abandonment was seen as reversible or not. Our analysis presents three types of abandonment: contingent, balanced and aversive. The figure below illustrates this typology:

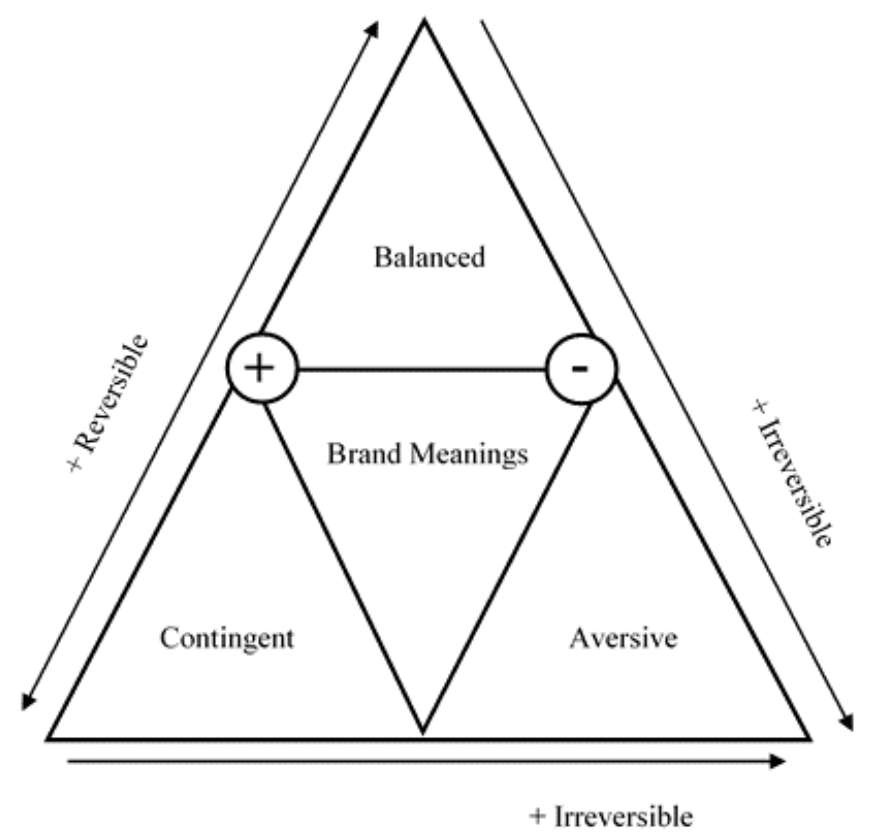

Figure 1. Abandonment Typology

Source: the authors.

\section{Contingent abandonment}

Although consumers identify themselves with the brand, they do not consume it anymore due to situational or external factors beyond their control. Abandonment may be motivated by competitors' 
promotional efforts or access problems, which makes consumption inconvenient. Lack of time or space, as well as elements such as legal or health restrictions can also lead to this type of abandonment. In the figure above, contingent abandonment is situated on the left size, where positive brand meanings dominate consumers' repertoire. Since informants' mainly perceive positive associations with the brand, it is the most reversible abandonment. As soon the consumers remove barriers to consumption, they may reestablish a brand relationship.

Marcelo (43 years-old, entrepreneur) and his family, for instance, had no concerns about food and health issues and they always consumed Coca-Cola and Fanta, as well as sweets and candies in general. After a troubling diagnosis of high glucose and a doctor's recommendation to reduce sugar consumption, Marcelo decided to abandon regular Coke and migrate to other no sugar soft drink options. However, the abandonment of his preferred brand is extremely fragile and shaky since he eventually returns to the product:

"A hot, stuffy day, like today. Grab a Coca-Cola bottle, a glass with ice. It's sooo nice!!! The Coca-Cola zero is not the same."

Marcio (34 y.o., web designer) is an example of contingent abandonment of the Fiat brand. Recently married, he struggles to organize his new family budget. For this reason, his last decision to purchase a Ford Fiesta was solely guided by a "nice opportunity", according to his own words, since the used car was in good condition and at a great price. When asked about the Fiat brand, Márcio presents many positive experiences and even demonstrates a nostalgic preference for the brand, since it has been present in his life since his childhood.

Teresa (30 y.o., technology analyst) is another example of this type of abandonment. She demonstrates low involvement and knowledge about the automobile market. After divorcing, she decided to buy a Fiat Uno, motivated by her mother's positive experience with the brand. After five years, and despite being quite satisfied with her Uno, Teresa's next acquisition was Peugeot 207. During her purchase process, Teresa considered buying the new Fiat Palio, but as she explains: "the French car dealer was more aggressive, and offering a great deal". In the future, she would consider buying a Fiat again. Teresa's discourse presents many positive aspects of the Fiat brand and she analyzes her Peugeot acquisition as resulting from commercial conditions and her interest in variety/novelty seeking, instead of negative associations with the Fiat brand.

Contingent brand abandonment is similar to the concept presented by Suarez and Chauvel (2012) for category abandonment, since ex-consumers share with consumers the positive meanings repertoire related to consumption. The main difference is that the first is related to a specific brand, while the second occurs when the consumer distances him/herself from the entire category. Teresa sold her Fiat to buy a Peugeot. Marcelo continues to drink other soft-drink brands. Their brand abandonment is provisional and reversible, as they both appreciate and consider buying the brand again in the not too distant future.

\section{Balanced abandonment}

In this type, consumers no longer identify with the brand and do not want to consume it in the future, but accept doing so, if necessary. Interviewees' discourses consider both the positive and negative meanings associated with the brand. For this reason, in the figure above, balanced abandonment is situated at the intersection of positive and negative brand meanings.

Vanessa (55 y.o., teacher) has regularly consumed Coca-Cola since childhood, but the birth of her first grandchild raised many concerns related to health and stimulated her to rethink her eating habits. Worried about red dye in the Coca-Cola formula, she decided to abandon Coca-Cola for others soft drinks such as Guaraná, Kuat, and Sprite, which she considers less harmful:

"If you have to drink soda, prefer the ones with light color, because the dark color has a lot of chemical substances." 
Despite her negative perception about the brand, Vanessa has a conciliatory and rational discourse in relation to its consumption. She claims that she still might drink Coca-Cola at parties and occasions where it is the only option:

"I will not say that I never drink it. I do drink it, but I prefer to avoid it. If I go to a party and there is another soda, I take another soda."

Vanessa considers her decision as a personal one and avoids any judgmental statements about Coca-Cola consumers. When asked her opinion about a Coca-Cola consumer's profile, she simply states: "someone normal, nothing special, a person like you and me". The informant does not try to influence others in this regard. In fact, she eventually buys Coca-Cola to offer to friends and relatives when hosting a meeting at her home. Even in her close family, which includes her husband, children and grandchildren, she is very careful to express her opinion about the brand, trying to influence, while at the same time respecting others' preferences:

"If they [her grandchildren] want it, I'll say 'it's nice, but it's not advisable to drink a lot'. But I will not say 'don't drink it because it is harmful'. I don't have this neurosis, I think you have to have options."

Luciano (32 y.o., realtor) is married and has three small children. When deciding about a new car, he analyzed aspects such as space and convenience, since he uses the car to work and travel with his family. He dreams about powerful and flashy brands, such as BMW, but his actual acquisition is rational, after scrutinizing fuel consumption and repair costs. Although he had a Fiat Idea for practical reasons, he wanted a small car because he worked in a difficult parking area. He emotionally prefers large and sporty cars and so he did not think twice about changing his Fiat for a Volkswagen Voyage when the family grew. Luciano sees the Fiat brand as accessible, economic and efficient, but at the same time, small and unable to fulfill his desire for larger and more spacious automobile.

Balanced Abandonment is reversible since consumers still perceive the brand's positive meanings, although concurrently considering its negative aspects. Experiencing alternative options, consumers sometimes realize a brand's unique benefits, reestablishing its consumption in the future. In some cases, however, balanced abandonment can also represent an experience that amplifies a consumer's distance. Far from regular consumption, the consumer forgets its benefits, highlighting the negative associations that initially motivated abandonment. For this reason, balanced abandonment opens new experiences for consumers that can reduce and sometimes eliminate positive brand associations, as the following examples illustrate.

\section{Aversive abandonment}

This is characterized by strong brand rejection and a conviction about that abandonment. The exconsumers within this abandonment category do not see the brand as something positive, do not wish to consume it and would not accept under any circumstances returning to the brand or even a temporary relapse. In the figure above, aversive abandonment is present at the right corner, dominated by negative meanings. In aversive abandonment, informants link brand abandonment to their identity and so are more committed to this decision. No longer consuming a previously consumed brand becomes an important reference about who they are or wish to be and for this reason it tends to be more irreversible.

This is the case of Caio (31 y.o., administrative assistant) who was accustomed to drinking CocaCola since childhood. Until recently, he drank an average of two liters of Coca-Cola per day. Although he had always been thin, he nonetheless felt he had an unattractive, soft belly. Concerned about aesthetics, he started to exercise regularly and adopted a healthy diet.

Describing the typical consumer of Coca-Cola in a projective exercise, Caio stated his view of a "chubby" person as someone who "does not work out". Presenting overtly as someone who abandoned Coca-Cola, Caio describes what could be considered his own persona: a confident and hardworking person, who fights for his desires; a person with attitude, seeking something better for himself and actualizing his power to change. In his new, healthy and athletic life, Coca-Cola became an icon of his 
undesirable status. Coca-Cola abandonment plays an important role in Caio's self-concept. As possession disposition, brand abandonment can be consciously or unconsciously maneuvered by consumers as a means of facilitating role transitions and processes of identity reconstruction (Lastovicka \& Fernandez, 2005; Young, 1991).

Andressa (43 years-old, secretary) is another example of aversive brand abandonment. After having two different Fiat models within six years, she decided to buy a Volkswagen car. During her buying process, she visited a Fiat dealership twice, strongly considering the purchase of another Fiat. However, after deciding to buy the VW Fox model, she became an aversive abandoner of Fiat brand, declaring that if she won a Fiat in a drawing, she would rather sell it than use it. She also states a preference for returning to public transportation instead of owning another Fiat car.

"Never, would I go back to Uninho [in Portuguese a diminutive form of 'little Uno', referring to the small Fiat Uno model]. I'll be without a car, but I will not do it. I would ride the bus, I would ride a taxi, but I will not do it. I think I would not go back, I think we grow according to everything we have in life."

Johnson et al. (2011) maintain that anti-brand retaliatory behaviors are more frequent when the target brand is important to consumers' self-concept or self-image. In contrast, anti-brand actions are less likely when relationships are low in self-relevance, but high in trust, commitment, and satisfaction. In such cases, even after relationship dissolution, consumers seem less motivated to complain to third parties and give negative word-of-mouth comments. Andressa's speech suggests that the symbolic importance of brand abandonment can also affect future narratives. If, in the past, she was satisfied and even considered purchasing another Fiat model, current accounts emphasizing criticism serve to highlight her evolution as a consumer, an aspect that will be fully interpreted in the next section.

Aversive informants, like Caio and Andressa, were more motivated to posture the framing of their reasons for giving up brand consumption. Since the brand is associated with meanings opposed to those the consumers wish for themselves in the present, they tend to detract from their previously preferred brand. For the same reason, aversive abandoners do not consider any possible return to consumption.

\section{Discourses enacted by brand abandonment}

Interviews suggest two distinct brand abandonment discourses that go beyond the commonly accepted perspective of failures and relationship crises. The first one presents abandonment as an evolutionary process and is particularly salient in the car category. In soft drink cases, we found themes related to sovereignty, self-management and control as the most dominant bedrocks of brand abandonment. Both discourses will be presented in the ensuing sections.

\section{Brand abandonment as evolution}

Brazil is one of the most attractive markets in the automotive world, given its current size and growth potential. In the last 20 years, Brazilian consumers saw both models and brands multiply (Industry Report Automotive, 2012). Some of our informants still differentiate this multiplicity of brands based on their childhood scenarios when they were socialized into category consumption. In the interviews, it was common for the interviewees to make the association of Fiat, GM, Volkswagen and Ford as part of a national industry, since they were the first companies to enter the country marketplace. Even those who recognize the origin of these multinational automakers establish a different relationship with the big four and differentiate them from the imported brands, the ones that came more recently. The enduring trajectory of these brands in the country produces ambivalent perceptions about these brands. They inspire the greatest confidence and credibility in the Brazilian market, but, at the same time, represent less innovative, modern and sophisticated brands.

Recent economic development in the country stimulated the inclusion of more of the population in an expanding segment of consumer markets. Although buying a car is a statement of economic and social achievement, our informants discourse more significantly highlight car ownership as the entry ticket to this elite group or social class. The differentiation within this ever-expanding group is enhanced 
by the ability to trade-in and update the car often, thereby evolving in the portfolio of models and brands. We asked respondents to describe the profile of a consumer who keeps the same car brand. Frequently, it is described as someone who changes "six of one for half dozen of another". It could also be a person who was parked in life, a person living a simple and routine life, without adventure or opportunity. Bernardo (36 y.o., Production Coordinator) although enjoying the experience with his Fiat Uno, preferred to acquire a Renault Sandeiro: "avoiding an exchange for the same thing". In his next purchase, Bernardo dreams of buying a Honda. When asked about the profile of people repeating the same brand of automobile, he associates this behavior with a conservative and older consumer: "He is a simple guy. Humble in the social and economic sense".

Luciano (31 y.o., Realtor), as presented earlier, rationalizes the acquisition of his new car as motivated by his family growth. The projective technique exercise, however, also evidences a negative connotation related to those who continually sponsor or select the same brand: "He is 40 years old and works in a bank. His day is a routine thing, has no long trip over the weekend, has no adventure. At most, he goes to the mall with his wife to see a film. His life is a more monotonous thing; it is a dull thing. His kids are grown and they are no longer with him".

Our informants' discourses suggest that car categories in Brazil carry symbolic messages that express an evolution in consumers' lives. In this case, even when they feel satisfied with their current brand, they feel pressure to move to the next step. Carla (44 y.o., high school teacher) illustrates this movement. She purchased a Fiat Uno, her first automobile, when she was 19 years old and newly married. She describes the car as "inexpensive and easy to drive" and remained loyal for many years because "it was enough for me". Despite being very satisfied with the model, a desire to change slowly grew in her until she decided to trade her Fiat Uno for a Fiat Palio. Implying an evolutionary quality to the category, she describes the Palio as "the next car, at an accessible price that we could afford, more modern", as if somehow, it was a next step up from her Fiat Uno. When she replaced her car again, five years later, Carla decided to abandon once and for all the Fiat brand and bought a Honda Fit: "The situation was improving, the family needed more comfort, more space, the next car, still in the Fiat portfolio, was a Weekend, but the insurance was really expensive. At the time, I said I'm going to buy a Weekend', but then came the (HONDA) Fit, and between the Weekend and the Fit, both the same cost".

The search for improvement, more comfort, more space, more style, more status and always more of something, suggests brand abandonment as a natural and almost expected event in this category. Although claiming to have been satisfied with Fiat, Carla states that it would be difficult for her to go back to the brand. Carla says that she would go back to Fiat only if needed: "Only if things get really ugly, because I don't want to do it".

As Carla's comments suggest, in this social ideation, there is only one thing that could be worse than maintaining the same car and that is going backwards in the hierarchy of models and brands. It's interesting to notice her preference change, as she seems reluctant to consume the brand even after being a loyal consumer for 18 years and asserts her satisfaction throughout the period.

As with other informants, Carla seems to associate her consumption trajectory with her financial growth and family life trajectory. It makes sense if one considers that the automotive category is filled with symbolism for the consumers, who use it to build and strengthen their self-image in terms of status, gender, age and personality (Belk, 2004; DaMatta et al., 2010). "I'm not attracted by that car [Fiat]. I don't even want to look. I don't despise it, but it feels like there was another audience then, you know? You look for something else. Maybe someday I'll return due to a necessity, but not because I want to. If I can invest in a Honda car or a Fiat car, I prefer Honda, I won't go back to Fiat".

Carla sees herself today at a different level than in the past, and Fiat doesn't represent that position difference. At the same time, she describes the brand as "outdated", signaling something that stayed behind and is now somehow inferior to her view of herself and her social position and needs. She also describes current Fiat consumers as "younger, impulsive, financially unstable". That's the opposite image she has of Honda consumers, who are "more established, more stable". 
That evolutionary trajectory seems to be a common narrative among those interviewed and reflects a specific dynamic in this category. If category consumption is used to represent the consumer's achievements, it would be natural to expect a constant brand adoption-disadoption dynamic as those consumers move symbolically forward in their life trajectories. This seems to be related to the symbolic dynamic that Campos, Suarez, Nascimento and Molica (2015, p. 326) label a "longitudinal rite of passage", which refers to connected behaviors following a lengthwise and structured trajectory that expressively marks the individual's journey of social status transition. Evolution in brand portfolios seems to be particularly relevant in the recent Brazilian economic scenario, where the emerging classes can have access to the most popular models, pressuring traditional consumers to move in search of more sophisticated models and brands (Campos, Suarez, Nascimento, \& Molica, 2015).

In practice, throughout life, consumption trajectories may vary. This is the case with consumers who return to entry models when pursuing a more highly valued category such as buying a new house. The most sophisticated model can be replaced by humbler ones in a family that increases its car fleet, in order to include their kids consumption, when the kids first reach adulthood. Carla, for instance, although presenting a resistance to personally return to the Fiat brand, envisions for her daughters a trajectory similar to her own, based on her good experience with her first Uno. In the near future, like her parents, she considers helping them to buy their own car and Fiat is in Carla's repertoire of considerations as an affordable and reliable option: "I liked Fiat. I never had any problems. It was a cheap and safe car that took care of me, that served me very well. It became complicated after I had a child and you wanted to offer more comfort to myself and your family. But I would certainly consider buying a Fiat for my daughter, when she starts to drive".

As suggested by Fournier (2014), even if consumers break-up with a brand, the relationship continues and changes in form. Since this category is important to consumers' self-concept or selfimage, not only anti-brand retaliatory behaviors (Johnson, Matear, \& Thomson, 2011), but mainly distancing behaviors are frequently engaged in an individual's consumption history. In our informants' symbolic repertoire, car consumption should follow an evolutionary trajectory of models and brands. Once they move to another brand's portfolio ladder, their willingness to return to the previously consumed brand drops to near zero. For this reason, movement toward the simplest models, as deviations from the socially expected path, require consumers to explain and negotiate their choices. As suggested by Carla's example, articulating brand meanings to previously consumed brands elicits personal narratives of life evolution, and will also serve as a pedagogical tool for her kids in the near future. In this case, returning to the Fiat brand becomes a socially acceptable way to express to her daughters the importance of starting in a humble way, to work and evolve in life.

\section{Brand abandonment as sovereignty and control over consumption}

If brand abandonment as a symbol of personal and social class evolution appears as something natural and even expected in the car category, we found a different dynamic in the case of soft drinks. Our informants reported a more stable loyalty relationship with Coca-Cola. For many of them, consumption started in childhood and continued into adulthood, until the abandonment process began. In other words, consumption pace is not related to change and evolution, but based on taste preferences and maintaining habits.

In the last decades, recurrent statements from healthy experts present the negative aftereffects of the soft drink products (Hattersley et al., 2009). In this case, Coca-Cola abandonment seems to result from a loss in the legitimacy process (Humphreys \& Latour, 2013), caused by propagation and strengthening of doppelgänger brand images (Thompson et al., 2006).

Before deciding to abandon its consumption, many of our interviewees reported cumbersome feelings caused by criticism directed at soft drinks. In the brand abandonment process, consumers enter into a battle with an internal enemy, with conflicts emerging between what they are and what they believe they should be. As a result of that conflict, abandonment may sometimes involve some sacrifice. As in mythological and religious stories, some informants' accounts present definitive signs - messages 
suggesting that this consumption sin cannot be ignored by them anymore. Life event triggers such as family diseases or births, finally transform the discomfort caused by the health-related information into an effective reduction or definitive cessation of consumption.

Luis (28 y.o., operations supervisor) drank Coca-Cola since he was a child in spite of his grandmother's warnings. She used to clean marble with Coca-Cola to show him what it does to his stomach. It was only when Luis' grandfather had cancer that he finally decided to quit: "My grandpa was addicted to soft drinks, he developed stomach cancer and the doctor said that it could have been caused by the Coca-Cola. I drink lemon sodas exactly because they are clear and don't have those dyes".

For Luis, Coca-Cola previous consumption was not a matter of lack of informational material or familial incentives. However, through his grandfather's example, he could finally experience the punishment for his consumption sin. Coca-Cola abandonment then became the moral obligation to reestablish responsibility for his own health and to guarantee that his grandfather's suffering had not occurred in vain. The negotiation of consumption legitimacy permeates Luis discourse, when suggesting restrictions to Coca-Cola and comparing it to an addiction: "The children should not drink Coca-Cola, the elderly should not drink Coca Cola, pregnant women cannot take Coca-Cola. When I have my own kids, I will not include it in their diet. If they want, they will drink it after, as teenagers, but it will not be my choice... Because I could free myself, but most people still drink a lot of Coca Cola, are addicted".

Luis' abandonment also became a moral aversion, as described by Lee et al. (2009) since he uses his personal history to discuss brand legitimacy on a societal level. In Luis' case, his ideological abandonment (Suarez \& Chauvel, 2012) is not based on nationalistic arguments or international capitalism critiques, as evidenced by Varman and Belk (2009) in India. Instead, his concern is based on the addictive and harmful effects on health.

Luana (31 y.o., high school teacher) was pregnant when advised by her physician to avoid specific foods and drinks, including Coca-Cola. She decided to totally stop her consumption of the brand. Although for years she had heard about the potential harm from the drink, not even a strong motivator such as aesthetics and personal well-being had been enough to separate her from the brand. The risk of harming her baby was what finally drove her to abandon Coca-Cola: "When I got pregnant, I went to my obstetrician to do a pre-natal and she said 'things that you should avoid. Not stop, but avoid: fritters, sodas'. I started avoiding. There was a period of 4, 5 months of pregnancy, that even if I tried to drink Coca-Cola it didn't feel good".

Pregnancy seems to offer a special, almost magical nuance within the Coca-Cola abandonment process. Imbued with meanings usually associated with this moment, such as nature's cycle, creation, connection to the body and life care, Luana finally felt in her body what was only accessed cognitively before. This bodily experience, plus the value of the maternal care of her baby, made Coca-Cola abandonment definitive, even if the doctor's recommendation had been just to reduce its consumption.

The Luis and Luana's examples align with Massyliouk and Campos' (2016) findings, presenting a series of strategies that parents use to control child consumption. These strategies include purchasing control; passing through the control of the storage and inclusion in the menu; and finally, the discourses and example of the adults in the family. In this sense, rather than an individual control aspect, Coca Cola abandonment presents itself as a mechanism of family consumption control and a pedagogical tool for teaching the youngest about health and nutrition.

The ability to exercise self-reliance and control, while managing consumption choices, became a moral value of contemporary societies characterized by affluence (Slater, 2002). This is also illustrated by Caio's example (31 y.o., administrative assistant), presented earlier. Since Coca-Cola consumption no longer fits his new, healthy and athletic life, the brand conflicts with the new image he desires for himself. Through Coca-Cola abandonment, Caio also creates a narrative of strength and transformation.

Through the rupture process with a brand, informants like Luis, Luna and Caio enact the heroic consumer standpoint (Slater, 2002). Instead of being enslaved by consumption, they present themselves as rational and sovereign in defining and meeting their needs and controls their own body and choices. 
In this context, brand abandonment creates a discursive platform where consumers present themselves as the ultimate authorities, exercising self-reliance and control, while managing consumption choices.

The two narratives herein presented - evolution and sovereignty/control - are not mutually exclusive. In the Fiat brand abandonment, our interviewees also express their rationality, independence and control. Likewise, in the Coca-Cola abandonment it is possible to identify elements that suggest a positive change and evolution as consumers who have improved into a healthier lifestyle. By emphasizing the association of each brand with specific discourses, however, the present research evidences that the abandonment has expressive nuances determined by "nodal points" (Kozinets, 2008 as cited in Žižek, 1989, p. 125). These may be metaphorically designated as centers of gravity around which abandonment symbolically develops.

As our analysis suggests, these specific nodal points are created through the interaction with the brand's cultural resonance (Fournier, Solomon, \& Englis, 2008), including aspects such as meanings carried by the brand, its consumers' stereotypes or roles and category resonance, among many other dimensions. Thus, our research evidences that brand abandonment goes beyond the relations established between the consumer and a specific brand in a direct and dyadic way, governed only by relations of satisfaction and dissatisfaction. Instead, we evidence a broader articulation including the range of products and meanings offered by cultural and social contexts and specific market dynamics. In this sense, each brand needs to develop a sensitivity to the gears that trigger distancing movements.

We illustrate this point by examining, for example, the repercussions and effects of category resonance (Fournier et al., 2008) on brand abandonment. Soft drink preference is usually molded during childhood through family or friends and perpetuated through taste and habit. Consumers can remain loyal to a certain brand for the rest of their lives without being considered monotonous or stagnant. Abandonment in this case is triggered by novel elements, in a process described by Fournier (1998) as stress model dissolution. According to the Fournier (1998), stress model assumes that at some point an element is included in the relationship, causing a stress that ultimately leads to abandonment. As our analysis suggests, Coca-Cola consumption is under constant attack, becoming socially reprimanded and politically incorrect (Massyliouk \& Campos, 2016; Varman \& Belk, 2009). In this context, caused by changes in the status quo and market scenario, consumers start to rethink preferences and habits related to the brand. Any issue or event of minor significance might serve as a trigger to start brand switching or, in some cases, the category abandonment process.

In contexts where an evolutionary narrative predominates, such as in the automobile category, abandonment is the engine of consumer differentiation. The exchange of brands is expected, as a way of highlighting an evolving consumer. In this case, abandonment is not caused by an important change in the market or an unexpected crisis, but is inherent in the fundamental dynamic of the market itself. Within the car category, evolution may be accomplished in either one of two ways. The first we refer to as horizontal evolution, which is an ascension within the same brand's portfolio, for instance, moving from a Fiat Uno to a Fiat Palio. The second, called vertical evolution, is ascending through the brand switching process.

In this case, what symbolically represents the consumption evolution is not necessarily the replacement of a product for other more expensive, but of one brand for another considered to be superior. While horizontal evolution implies the purchase of a more expensive car than the one previously owned, with vertical evolution that is not necessarily true. Replacing one brand for another in and of itself sometimes generates this feeling of improvement. Thus consumers may trade a car from brand (A) for a car from brand (B) at the same price and still fulfill this symbolic need for evolution. 


\section{Final Comments}

Instead of presenting abandonment narrowly, as a rupture or using the divorce metaphor, the present research expands our understanding of this topic by describing the discursive nuances of the brand abandonment process. Through investigation of emblematic brands, the analysis depicts cultural discourses that consumers use to give meanings to their experiences of giving up previously consumed brands.

This study presents brand abandonment as an enabler of social distinctions and narratives such as evolution, change and self-determination. The analysis suggests that brand abandonment, as possession disposition (Lastovicka \& Fernandez, 2005; Young, 1991), can serve as a means of facilitating role transitions and processes of identity reconstruction. This research evidences brand abandonment as a more complex phenomenon that goes beyond dissatisfaction, but instead is infused in broader ideologies such as affluence (Hirschman, 1990; Veblen, 1988), rationality and sovereignty (Slater, 2002).

The study identifies three differing types of brand abandonment: contingent, balanced and aversive, evidencing nuances of brand distancing behaviors. This abandonment typology demonstrates that not all distancing behaviors arise from definitive ruptures within the brand meanings repertoire. Some consumers continue loving the brand, even after becoming ex-consumers, as in the case of contingent abandonment. On the opposite side, aversive abandoners may become detractors, as suggested by previous studies (Johnson et al., 2011; Lee, Motion, \& Conroy, 2009).

Our study presents two cultural discourses underlying brand abandonment. In the first, brand abandonment has the symbolic task of serving as a marker of consumer life evolution. If consumption is used to represent the consumer's achievements, it would be natural to expect a constant brand adoption-disadoption dynamic as those consumers move symbolically forward with their life cycle trajectories. The second discourse embraces the cultural controversy over whether consumption is a matter of manipulation or freedom, whether the consumer is sovereign or subject. In this narrative, brand abandonment serves as evidence of rationality, self-control and consumer sovereignty. These two discourses offer countervailing models for interpreting brand relationships, creating new meanings to the brands and brand abandonment itself. The present research contributes to evidence of the cultural complexity of the consumer experience and behavior, linking the narratives to the larger ideologies that legitimize brand abandonment process.

Companies invest a great deal of effort into building strong brands, molding discourses around brand value and creating a sense of indispensability in consumer's lives. This present research highlights a less evident dynamic in which consumers assemble divergent narratives, based on contemporary ideologies, justifying their distancing behavior from these brands. In this sense, abandonment discourses can be understood as creative work to overcome the current messages created by advertising. One valuable aspect of the present research is the analysis of discourses created not by anti-brand activists, but by regular ex-consumers in their everyday and routine and discursive practices attributing meanings to their experiences with existing brands. Instead of countercultural or resistant logics, life evolution and sovereignty/control discourses may become a powerful representation of brand abandonment exactly because they are rooted in status-quo ideologies.

The research also demonstrates that brand abandonment can be fostered by the loss of legitimacy caused by propagation and strengthening of doppelgänger brand images (Thompson et al., 2006). In this case, brands still appreciated and established as preference in consumers' lives can become founts of conflict, which abandonment aims to solve.

The present study has various limitations and it is important to highlight some of them. This research captures the discourse of ex-consumers and their narratives about the abandonment of previously consumed brands. This cultural discourse, however, is neither individual nor constructed exclusively by consumers, but rather is an articulation including different actors from the market, such as industry professionals, doctors, trade associations, journalists, bloggers, among others. Future studies 
can map the construction and nuances of brand abandonment discourses presented here, as well as new perspectives from the research with other market agents.

Investigation that looks not only at the discursive aspects of the process but also practical and material limitations clearly differs from the approach in this research. The emphasis on the discursive aspects did not contemplate more concrete aspects of the brand abandonment behavior. Future research may investigate how the process of abandoning certain consumption impacts practices and consumers' daily routines. In this case, the use of other research methods such as observation would be essential.

The field research was undertaken in the context of Rio de Janeiro. Although we advocate for the theoretical relevance of the constructs presented here, there was no intention to generalize the results to any given population group. Since the research also focused on automobiles and soft drinks consumption, future studies can compare and contrast our findings with different categories, including services as well. Important differences may arise when investigating distancing behaviors that create greater perception of risk, such as abandoning medicines or health insurance plans, for instance.

Challenging the commonly accepted perspective of brand abandonment as the result of failures and relationship crisis also opens new avenues for research about this topic. Few studies have focused on the brand abandonment process and more research is needed in this area. Although we have presented three different types of brand abandonment, an integrative theory of this process and factors triggering breakdowns remains a theoretical challenge. Fully understanding forces that maintain established patterns of consumption and the ones that propel abandonment will have to be addressed by future research. Another interesting topic of research relates to expiration of barriers to brand abandonment following a consumer's affirmative decision to do so. An unanswered question is why certain brands are harder to abandon than others. Finally, Johnson et al. (2011) investigated relations between antibrand retaliatory behaviors and brand relevance on consumers' self-concept or self-image. Future studies might also consider the symbolic importance of the abandonment process itself, investigating how distancing behavior processes affect future brand testimonials, complaints and word-of-mouth behaviors.

\section{References}

Allen, C. T., Fournier, S., \& Miller, F. (2008). Brands and their meaning makers. In C. P. Haugtvedt, P. M. Herr, \& F. R. Kardes (Eds.), Handbook of consumer psychology (pp. 781-822). New York: Lawrence Erlbaum Associates.

Anderson, M. H., \& Jaggia, S. (2012). Return, purchase, or skip? Outcome, duration, and consumer behavior in the rent-to-own market. Empirical Economics, 43(1), 313-334. http://dx.doi.org/10.1007/s00181-011-0461-4.

Arnould, E. J., \& Thompson, C. J. (2015). Consumer culture theory: Ten years gone (and beyond). In A. Thyraff, J. B. Murray, \& R. W. Belk (Orgs.), Research in consumer behavior (pp. 1-21). Bingley, UK: Emerald.

Arsel, Z., \& Bean, J. (2013). Taste regimes and market-mediated practice. Journal of Consumer Research, 39(5), 899-917. http://dx.doi.org/10.1086/666595

Arsel, Z., \& Thompson, C. J. (2011). Demythologizing consumption practices: How consumers protect their field-dependent identity investments from devaluing marketplace myths. Journal of Consumer Research, 37(5), 791-806. https://doi.org/10.1086/656389 
Associação Brasileira das Indústrias de Refrigerantes e de Bebidas não Alcoólicas (n.d.). Refrigerantes. Retrieved from http://abir.org.br/o-setor/dados/refrigerantes/

Belk, R. W. (2004). Men and their machines. Advances in Consumer Research, 31, 273-278. Retrieved from http://www.acrwebsite.org/volumes/v31/acr_vol31_96.pdf

Belk, R., Fischer, E., \& Kozinets, R. V. (2012). Qualitative consumer and marketing research. London: Sage.

Bristor, J. M., \& Fischer, E. (1993). Feminist thought: Implications for consumer research. Journal of Consumer Research, 19(4), 518-526. https://doi.org/10.1086/209320

Campos, R., Suarez, M., Nascimento, T. do, \& Molica, F. (2015). I am dreaming of a car: Longitudinal rites of passage and car consumption. Advances in Consumer Research, 43, 324-328. Retrieved from http://www.acrwebsite.org/volumes/v43/acr_vol43_1019959.pdf

DaMatta, R., Vasconcelos, J. G. M., \& Pandolfi, R. (2010). Fé em Deus e pé na tábua, ou Como e por que o trânsito enlouquece no Brasil. Rio de Janeiro: Rocco.

Desjeux, D., Suarez, M., \& Campos, R. D. (2014). The itinerary method: A methodological contribution from social sciences to consumer research in management. Revista Brasileira de Marketing, 13(2), 74-83. https://doi.org/10.5585/remark.v13i2.2677

Dwyer, F. R., Schurr, P. H., \& Oh, S. (1987). Developing buyer-seller relationships. The Journal of Marketing, 51(2), 11-27. https://doi.org/10.2307/1251126

Fischer, E., Castilhos, R., \& Fonseca, M. (2014). Entrevista qualitativa na pesquisa de marketing e do consumidor: Abordagens paradigmáticas e orientações. Revista Brasileira de Marketing, 13(4), 67-79. https://doi.org/10.5585/remark.v13i4.2762

Fournier, S. (1998). Consumers and their brands: Developing relationship theory in consumer research. Journal of Consumer Research, 24(4), 343-353. https://doi.org/10.1086/209515

Fournier, S. (2014). Breaking up is hard to do: The ups and downs of divorcing brands. GfK Marketing Intelligence Review, 6(1), 28-33. https://doi.org/10.2478/gfkmir-2014-0005

Fournier, S., Alvarez, C., \& Avery, J. (2012). Disadoption through the relationship lens. Proceedings of the Association for Consumer Research Conference, Chicago, IL, USA.

Fournier, S., Solomon, M., \& Englis, B. (2008). When brands resonate. In B. H. Schmitt \& D. Rogers (Eds.), Handbook of brand and experience management (pp. 35-57). Cheltenham, UK: Edward Elgar.

Giesler, M. (2012). How doppelgänger brand images influence the market creation process: Longitudinal insights from the rise of botox cosmetic. Journal of Marketing, 76(6), 55-68. https://doi.org/10.1509/jm.10.0406

Hattersley, L. A., Shrewsbury, V. A., King, L. A., Howlett, S. A., Hardy, L. L., \& Baur, L. A. (2009). Adolescent-parent interactions and attitudes around screen time and sugary drink consumption: A qualitative study. International Journal of Behavioral Nutrition and Physical Activity, 6, 1-8. https://doi.org/10.1186/1479-5868-6-61

Hirschman, E. C. (1990). Secular immortality and the American ideology of affluence. Journal of Consumer Research, 17(1), 31-42. https://doi.org/10.1086/208534

Hogg, M. K., Banister, E. N., \& Stephenson, C. A. (2009). Mapping symbolic (anti-) consumption. Journal of Business Research, 62(2), 148-159. https://doi.org/10.1016/j.jbusres.2008.01.022 
Holt, D. B. (2005). Como as marcas se tornam ícones: Os princípios do branding cultural. São Paulo: Cultrix.

Holt, D. B. (2006). Jack Daniel's America iconic brands as ideological parasites and proselytizers. Journal of Consumer Culture, 6(3), 355-377. https://doi.org/10.1177/1469540506068683

Hulbert, J., Pitt, L., \& Ewing, M. (2003). Defections, discourse and devotion: Some propositions on customer desertion, dialogue and loyalty. Journal of General Management, 28(3), 43-51. https://doi.org/10.1177/030630700302800303

Humphreys, A. (2010). Megamarketing: The creation of markets as a social process. Journal of Marketing, 74(2), 1-19. https://doi.org/10.1509/jmkg.74.2.1

Humphreys, A., \& Latour, K. A. (2013). Framing the game: Assessing the impact of cultural representations on consumer perceptions of legitimacy. Journal of Consumer Research, 40(4), 773-795. https://doi.org/10.1086/672358

Instituto Brasileiro de Geografia e Estatística. (2014). Pesquisa nacional de saúde 2013: Percepção do estado de saúde, estilos de vida e doenças crônicas - Brasil, Grandes Regiões e Unidades da Federação. Rio de Janeiro, RJ: Autor.

Industry Report Automotive. (2012). Brazil. The Economist Intelligence Unit, 4(2), 1-13.

Izberk-Bilgin, E. (2012). Infidel brands: Unveiling alternative meanings of global brands at the nexus of globalization, consumer culture, and Islamism. Journal of Consumer Research, 39(4), 663687. https://doi.org/10.1086/665413

Jiang, Y., Zhan, L., \& Rucker, D. D. (2014). Power and action orientation: Power as a catalyst for consumer switching behavior. Journal of Consumer Research, 41(1), 183-196. https://doi.org/10.1086/675723

Johnson, A. R., Matear, M., \& Thomson, M. (2011). A coal in the heart: Self-relevance as a post-exit predictor of consumer anti-brand actions. Journal of Consumer Research, 38(1),108-125. https://doi.org/10.1086/657924

Kozinets, R. V. (2008). Technology/Ideology: How ideological fields influence consumers' technology narratives. Journal of Consumer Research, 34(6), 865-881. https://doi.org/10.1086/523289

Lastovicka, J. L., \& Fernandez, K. V. (2005). Three paths to disposition: The movement of meaningful possessions to strangers. Journal of Consumer Research, 31(4), 813-823. https://doi.org/10.1086/426616

Lee, M.S.W., Motion, J., \& Conroy, D. (2009). Anti-consumption and brand avoidance. Journal of Business Research, 62(2), 169-180. https://doi.org/10.1016/j.jbusres.2008.01.024

Lehmann, D., \& Parker J. (2012). Disadoption. Advances in Consumer Research, 40, 313-314. Retrieved from http://www.acrwebsite.org/volumes/v40/acr_v40_13116.pdf

Lemmens, A., \& Croux, C. (2006). Bagging and boosting classification trees to predict churn. Journal of Marketing Research, 43(2), 276-286. https://doi.org/10.1509/jmkr.43.2.276

Massyliouk, M. F. da F., \& Campos, R. D. (2016). Faça o que eu digo, não faça o que eu faço: A relação entre adultos na socialização infantil no consumo alimentar. Revista Brasileira de Marketing, 15(4), 474-485. https://doi.org/10.5585/remark.v15i4.3409

McCracken, G. (1988). The long interview. Newbury Park, CA: Sage. 
Moisander, J., Valtonen, A., \& Hirsto, H. (2009). Personal interviews in cultural consumer research post-structuralist challenges. Consumption Markets \& Culture, 12(4), 329-348, https://doi.org/10.1080/10253860903204519

Muñiz, A. M., Jr., \& Schau, H. J. (2005). Religiosity in the abandoned apple newton brand community. Journal of Consumer Research, 31(4), 737-47. https://doi.org/10.1086/426607

Parmentier, M. A., \& Fischer, E. (2015). Things fall apart: The dynamics of brand audience dissipation. Journal of Consumer Research, 41(5), 1228-1251. https://doi.org/10.1086/678907

Prentice, C. (2014). Who stays, who walks, and why in high-intensity service contexts. Journal of Business Research, 67(4), 608-614. https://doi.org/10.1016/j.jbusres.2013.02.044

Reckwitz, A. (2002). Toward a theory of social practices. European Journal of Social Theory, 5(2), $243-$ 263. https://doi.org/10.1177/13684310222225432

Rook, D. W. (2006). Let's pretend: Projective methods reconsidered. In R. W. Belk (Ed.), Handbook of qualitative research methods in marketing (pp. 143-155). Cheltenham, UK: Edward Elgar Publishing.

Schroeder, J. (2015) Brands: Interdisciplinary perspectives. New York: Routledge.

Slater, D. (2002). Cultura do consumo \& modernidade. São Paulo: Nobel.

Suarez, M. C. (2014). Meanings of consumption and abandonment: Understanding smoking cessation symbolism. Brazilian Administration Review, 11(2), 210-227. Retrieved from http://www.scielo.br/pdf/bar/v11n2/v11n2a06.pdf. $\quad$ http://dx.doi.org/10.1590/S180776922014000200006

Suarez, M. C., \& Casotti, L. M. (2015). Transcendendo a abordagem individual do consumo: Uma investigacao dos significados do automovel pela perspectiva das famílias. Brazilian Business Review, 12(2), 87-109. http://dx.doi.org/10.15728/bbr.2015.12.2.5

Suarez, M. C., \& Chauvel, M. A. (2012). Different ways of saying goodbye: Outlining three types of abandonment of a product category. In R. Belk, S. Askegaard, \& L. Scott (Eds.), Research in consumer behavior (Vol. 14, pp. 277-295). Bingley: Emerald.

Suarez, M., \& Belk, R. (2017) Cultural resonance of global brands in Brazilian social movements. International Marketing Review, 34(4), 480-497. https://doi.org/10.1108/IMR-07-2014-0252

Thompson, C. J. (1997). Interpreting consumers: A hermeneutical framework for deriving marketing insights from the texts of consumers' consumption stories. Journal of Marketing Research, 34(4), 438-455. https://doi.org/10.2307/3151963

Thompson, C. J. (2004). Marketplace mythology and discourses of power. Journal of Consumer Research, 31(1), 162-180. https://doi.org/10.1086/383432

Thompson, C. J., Rindfleisch, A., \& Arsel, Z. (2006). Emotional branding and the strategic value of the doppelgänger brand image. Journal of Marketing, 70(1), 50-64. https://doi.org/10.1509/jmkg.2006.70.1.50

Varman, R., \& Belk, R. W. (2009). Nationalism and ideology in an anticonsumption movement. Journal of Consumer Research, 36(4), 686-700. https://doi.org/10.1086/600486

Veblen, T. (1988). A teoria da classe ociosa: Um estudo econômico das instituições. São Paulo: Nova Cultural. 
Young, M. M. (1991). Disposition of possessions during role transitions. Advances in Consumer Research, 18, 33-39. Retrieved from http://acrwebsite.org/volumes/7131/volumes/v18/NA-18

Wilk, R. R. A. (1997). Critique of desire: Distaste and dislike in consumer behavior. Consumption Markets \& Culture, 1(2), 175-196. https://doi.org/10.1080/10253866.1997.9670297

Žižek, S. (1989). The sublime object of ideology. London: Verso.

\section{Authors' Profiles}

Fillipe Diniz

Rua Pascoal Lemme, 355, Ilha do Fundão, 21941-972, Rio de Janeiro, RJ, Brazil. E-mail address: filliped@ yahoo.com. https://orcid.org/0000-0002-8345-5240

Maribel Carvalho Suarez

Rua Pascoal Lemme, 355, Ilha do Fundão, 21941-972, Rio de Janeiro, RJ, Brazil. E-mail address: maribels@ coppead.ufrj.br. https://orcid.org/0000-0001-9736-5273 